\title{
2,4-D Ethyl Ester Poisoning: A Case Report
}

\author{
Nishant Kumar
}

\section{Abstract}

2,4-Dichlorophenoxyacetic acid (2,4-D) is a herbicide with highly toxic effects. Complications occur due to difficulty in diagnosis. Management is only supportive with alkaline diuresis and treatment of complications as there is no specific antidote to this compound.

Keywords: 2,4-Dichlorophenoxyacetic acid, Alkaline diuresis, Poisoning

Indian Journal of Critical Care Medicine (2019): 10.5005/jp-journals-10071-23240

\section{INTRODUCTION}

There are many pesticides available for farming purpose. 2,4-D is a herbicide of chlorophenoxy herbicide group widely used in northern India against broad-leaf weeds in cereal crops, lawns and parks. Ingestion, skin contact and inhalation are three main route of human exposure to 2,4-D herbicides. ${ }^{1}$ Very few documented poisoning cases with this compound have been reported. Misdiagnosis chances are high as initial symptoms can mimic that of anticholinesterase poisoning.

Acute lethal levels of 2,4-D in the plasma appear to lie between $447 \mathrm{mg} /$ liter and $826 \mathrm{mg} /$ liter. Its toxic effects involve heart, central and peripheral nervous systems, liver, kidneys, muscles, lungs and endocrine system, ${ }^{2}$ and there is no specific antidote for $2,4-D$ herbicide poisoning. ${ }^{3}$ Blood levels of 2,4-D can be measured most accurately with gas-liquid chromatography with electron-capture detection (GLC-EC).

\section{Case Description}

A 17-year-male patient presented to us 13/01/2017 at $5.30 \mathrm{pm}$ with complaints of nausea, vomiting without blood, abdominal pain and loss of consciousness after 2 hours of oral ingestion of about $150 \mathrm{~mL}$ of a herbicide with brand name of cutout- 38 whose active ingredient is 2,4-D ethyl ester. However, there was no fasciculation, diarrhoea, lacrimation/salivation or lung crepitations.

His blood pressure was $130 / 80 \mathrm{~mm} \mathrm{Hg}$ and pulse rate was $108 / \mathrm{min}$. Respiratory rate was $20 / \mathrm{min}$ and pupils were mid dilated and reactive. Bilateral chest auscultation revealed vesicular breath sounds. ECG showed sinus tachycardia. Initial neurological assessment revealed Glasgow coma scale (GCS) of 10. Immediately gastric lavage with charcoal was done.

His hemoglobin was $16.1 \mathrm{mg} / \mathrm{dL}$, total leukocyte count was 18400 , and platelet count was $2.48 \mathrm{lakh} / \mathrm{mm}^{3}$. His liver and renal functions were normal. ABG showed metabolic alkalosis. Blood levels of 2,4-D could not be measured as the required facility was not available.

This poison does not have any specific antidote. Literature search resulted in finding a role of forced alkaline diuresis in its management. We started treatment with intravenous fluids, sodium bicarbonate and injectable furosemide to cause forced diuresis.

Gradually sensorium improved and urine output was maintained. Tachycardia resolved after 4 hours. Next day, patient was hemodynamically stable with a GCS of 15 .
Department of Critical Care Medicine, Santevita Hospital, Ranchi, Jharkhand, India

Corresponding Author: Nishant Kumar, Department of Critical Care Medicine, Santevita Hospital, Ranchi, Jharkhand, India, Phone: 917838420448, e-mail: nishantn23113@gmail.com

How to cite this article: Kumar N. 2,4-D Ethyl Ester Poisoning: A Case Report. Indian J Crit Care Med 2019;23(9):432-433.

Source of support: Nil

Conflict of interest: None

Alkaline diuresis and other treatments were continued. The patient was discharged from hospital after 3 days of admission being hemodynamically stable and with normal laboratory tests.

\section{Discussion}

The main routes of exposure of phenoxy compounds are skin, inhalation and oral ingestion. The exact mechanism of phenoxy herbicides toxicity is unclear. These compounds are irritants and cause corrosive effects in gastrointestinal tract causing nausea, vomiting, abdominal or throat pain and diarrhea. They also cause neuromuscular toxicity and myotonia through inhibition of the voltage-gated chloride channel (CLC-I) in skeletal muscles. ${ }^{4}$

Metabolic acidosis, hyperventilation, hyperkalemia, hyperthermia, elevated creatine kinase, generalized muscle rigidity, hypotension or asystole are criteria of severe toxicity. ${ }^{5}$

Various mechanisms of toxicity including dose-dependent cell membrane damage, uncoupling of oxidative phosphorylation and disruption of acetyl coenzyme A metabolism have been proposed. ${ }^{5}$

Unconsciousness or coma may result from a direct CNS depressant action or metabolic derangements in patients. Hypertonia, hyperreflexia, ataxia, nystagmus, miosis, hallucinations, convulsions, fasciculation and paralysis may present at variable intervals during the course of systemic toxicity. ${ }^{6}$

Our case showed good response with urine alkalinization. Urine alkalinization is one form of enhance elimination that may be useful in some poisoning such as phenobarbital, chlorpropamide, salicylate, chlorophenoxy herbicides specially 2,4-dichlorophenoxy acetic acid and mecoprop. ${ }^{5}$

Since myoglobinuria produces nephrotoxicity, alkaline diuresis also may be helpful in preventing renal damage. Chlorophenoxy herbicides are weak acids ( $\mathrm{pKa}=2.6$ for 2,4-D) and excreted in the urine unchanged. Alkaline diuresis especially in severe $2,4-D$ poisoning may be lifesaving. ${ }^{8}$

(C) The Author(s). 2019 Open Access This article is distributed under the terms of the Creative Commons Attribution 4.0 International License (https://creativecommons. org/licenses/by-nc/4.0/), which permits unrestricted use, distribution, and non-commercial reproduction in any medium, provided you give appropriate credit to the original author(s) and the source, provide a link to the Creative Commons license, and indicate if changes were made. The Creative Commons Public Domain Dedication waiver (http://creativecommons.org/publicdomain/zero/1.0/) applies to the data made available in this article, unless otherwise stated. 
Plasma alkanalization may also limit the distribution of phenoxy compounds from the central circulation by ion trapping.,

The poison is highly fatal with the mortality reaching almost $100 \%$ in the reports from the rest of the world. ${ }^{10}$ Our patient fortunately had only gastrointestinal effects at presentation and no pulmonary, renal or myotoxic effects.

Probably, vomiting after ingestion helped the patient in reducing absorbed dose of poison and forced alkaline diuresis initiated helped in rapid recovery of our patient.

\section{Conclusion}

It is a potentially fatal poison and the most effective way of identifying the poison is to look at the container or the literature available with the container. Clinical presentation can mimic of those of anticholinesterase poisoning so a careful search for presence of signs of corrosive injury, muscle weakness (proximal $>$ distal) and neuropathies will help in identifying cases with 2,4-D ingestion. Severe toxicity symptoms should be in mind and an alkaline diuresis can increase herbicide elimination.

\section{References}

1. Dinamarca VM, Hidalgo ME, Cavieres MF. Lack of effects of 2,4-dichlorophen-oxyacetic acid administration on markers of oxidative stress during early pregnancy in mice. Toxicology. 2007;237(1-3):104-110.
2. Kumar $\mathrm{H}$, et al. A case of 2,4-Dichlorphenoxyacetic acid (2,4-D) ingestion masquerading anticholinesterase poison. IJRRMS 2013;3(2).

3. Bradberry SM, Watt BE, Proudfoot AT, Vale JA. Mechanisms of toxicity, clinical features, and management of acute chlorophenoxy herbicide poisoning: a review. J Toxicol Clin Toxicol. 2000;38(2):111-122.

4. Aromataris EC, Astill DS, Rychkov GY, Bryant SH, Bretag AH, Roberts ML. Modulation of the gating of CIC-1 by S-(-) 2-(4-chlorophenoxy) propionic acid. Br J Pharmacology. 1999;126(6):1375-1382.

5. Bradberry SM, Proudfoot AT, Vale JA. Poisoning due to chlorophenoxy herbicides. Toxicology Rev. 2004; 23(2):65-73.

6. Roberts DM, Seneviratne R, Mohammed F, Patel R, Senarathna L, Hittarage $A$, et al. Intentional self-poisoning with the chlorophenoxy herbicide 4-chloro-2-methylphenoxyacetic acid (MCPA). Ann Emerg Med. 2005;46(3):275-284.

7. Flanagan RJ, Meredith TJ, Ruprah M, Onyon LJ, Liddle A., et al. Alkaline diuresis for acute poisoning with chlorphenoxy herbicides and ioxynil. Lancet. 1990;335:454-458.

8. Prescott LF, Park J, Darrien I. Treatment of severe 2,4-D and mecoprop intoxication with alkaline diuresis. Br J Clin Pharmacol. 1979;7(1): 111-116.

9. Prescott LF, Park J, Darrien I. Treatment of severe 2,4-D and mecoprop intoxication with alkaline diuresis. Br J Clin Pharmacol. 1979;7(1): 111-116.

10. Jearth Vaneet, Negi Rajan, Chauhan Vivek, Sharma Kailashnath, et al. A rare survival after 2,4-D (ethyl ester) poisoning: Role of forced alkaline diuresis. Indian Journal of Critical Care Medicine. January 2015 ; Vol 19 (Issue 1):57-58. 